\title{
Research Article \\ Effect of different culture media on growth characteristics of Cercospora beticola sacc, causing cercospora leaf spot of beetroot
}

\author{
Kandhi Mounika and Abhilasha A. Lal
}

\begin{abstract}
SUMMARY
Beetroot (Beta vulgaris L.) is a versatile crop; it can be grown in any season. It is also known as table beet, garden beet, and sugar beet. Beetroot crop is affected by number of fungal diseases. Cercospora leaf spot is the most devastating foliar disease caused by Cercospora beticola. Fungi grow on diverse habitat; it requires different specific elements for their growth and development in in vitro. In the present investigation three different culture media viz., Beetroot leaf extract agar media, Richards's agar media, and Potato dextrose agar media were tested against cercospora beticola to evaluate the effect of different culture media on growth characters of Cercospora beticola. The fungi showed difference in growth development when grown on different cultural media. Results obtained that the best fungal growth was observed in Richard's agar media and the minimum growth was observed in potato dextrose agar media.
\end{abstract}

Key Words : Beetroot, Cercospora, In vitro, Media, Growth, Cultural

How to cite this article : Mounika, Kandhi and Lal, Abhilasha A. (2021). Effect of different culture media on growth characteristics of Cercospora beticolasacc, causing cercospora leaf spot of beetroot. Internat. J. Plant Sci., 16 (1): 64-66, DOI: 10.15740/HAS/IJPS/ 16.1/64-66, Copyright@ 2021: Hind Agri-Horticultural Society.

Article chronicle : Received : 26.10.2020; Revised : 14.11.2020; Accepted : 16.12.2020

\section{MEMBERS OF THE RESEARCH FORUM}

\section{Author to be contacted :}

Kandhi Mounika, Department of Plant Pathology, Naini Agriculture Institute, Sam Higginbottom University of Agriculture Technology and Sciences, Prayagraj (U.P.) India

Email : kandi.mounikareddy99@gmail.com

\section{Address of the Co-authors:}

Abhilasha A Lal, Department of Plant Pathology, Naini Agriculture Institute, Sam Higginbottom University of Agriculture Technology and Sciences, Prayagraj (U.P.) India 